\title{
Effects of Different Applications on Postoperative Seroma Formation and Wound Healing Following Mastectomy and Axillary Dissection in Rats
}

\author{
Oktay Karaköse ${ }^{1^{*}}$ (D), Hüseyin Pülat ${ }^{2}$ (D), Kazım Çağlar Özçelik ${ }^{3}$ (D) İsmail Zihni ${ }^{4}$ (D), \\ Kemal Kürşat Bozkurt ${ }^{5}$ (D) Serdar Şenol ${ }^{6}$, Fatma Nihan Cankara ${ }^{7}$ (D), Hasan Erol Eroğlu ${ }^{4}$ (D)
}

\begin{abstract}
The most frequent postoperative complication after breast surgery is seroma formation. Seroma occurs due to lymphatic and vascular fluid leakage into the dead space created by surgical dissection.

The objective of the research was to evaluate the effects of local fibrin glue, tetracycline, talc applications, and flap fixation technique on reducing seroma formation after mastectomy and axillary dissection. In addition, we aimed to determine the level of efficacy for these applications, as well as to identify the most appropriate method to be used in operations with high risk of seroma formation.

Materials and Methods. This experimental study was conducted using a total of 60 female Wistar albino rats. They were allocated into six groups and each comprised ten rats. Unilateral mastectomy and axillary dissection were performed on all the rats. Local applications of fibrin glue, tetracycline, talc, and alcoholic iodine were performed in four separate groups. Flap fixation technique was applied in one group and those rats that did not receive any intervention constituted the control group. On the $10^{\text {th }}$ postoperative day, seroma was aspirated under anesthesia, and the amount of seroma fluid was recorded. Seroma fluid was analyzed for interleukin $1-\beta$, vascular endothelial growth factor, and C-reactive protein levels. Tissue samples were obtained from the skin overlaying the dissection area, the axilla, and the thoracic wall. Wound healing was evaluated with histopathological examination.

Results. Seroma volume was lower and the wound healing scores were the highest in the flap fixation group and the tetracycline group as compared to the control group. However, the alcoholic iodine group and the talc group had a greater amount of seroma $(p<0.05)$. There was no difference between the fibrin glue group and the control group.

Conclusions. In our mastectomy model, local application of alcoholic iodine and talc substances caused more wound site problems and postoperative seroma formation. While fibrin glue did not cause wound site problems, it did increase seroma formation. These three substances were determined to be inefficacious in postoperative seroma formation. Local tetracycline application and flap fixation technique were found to reduce postoperative seroma and benefit wound healing.
\end{abstract}

\section{Keywords}

Mastectomy; Seroma; Alcoholic lodine; Tetracycline; Flap Fixation Technique; Talc; Fibrin Glue

${ }^{1}$ Samsun Training and Research Hospital, Surgical Oncology Clinic, Samsun, Turkey

${ }^{2}$ Mersin City Hospital, Surgical Oncology Clinic, Mersin, Turkey

${ }^{3}$ Yenimahalle Training and Research Hospital, Surgical Oncology Clinic, Ankara, Turkey

${ }^{4}$ Süleyman Demirel University, Faculty of Medicine, Surgical Oncology Clinic, Isparta, Turkey

${ }^{5}$ Süleyman Demirel University, Faculty of Medicine, Department of Pathology, Isparta, Turkey

${ }^{6}$ Samsun Training and Research Hospital, Gastroenterological Surgery Clinic, Samsun, Turkey

${ }^{7}$ Süleyman Demirel University, Faculty of Medicine, Institute of Health Sciences, Department of Pharmacology, Isparta, Turkey

*Corresponding author: oktaykarakose@gmail.com 


\section{Problem statement and analysis of the latest research}

Breast cancer is currently the most common cancer among women. The lifetime risk of breast cancer in women is 12$13 \%$, and one in every eight women is at risk of developing breast cancer [1]. The gold standard for treatment is surgery, although several complications may develop in all surgical interventions. These are mainly wound infection, hematoma, seroma, nerve injury, and lymphedema. They all occur more frequently after mastectomy and axillary dissection. The most common complication is seroma, with a prevalence ranging from $10 \%$ to $50 \%[2,3]$. Seroma can develop after any surgical procedure that involves preparation of a skin flap and occurs as a result of lymphatic or vascular fluid leakage into the dead space created by surgical dissection [4]. Although there is no clear definition of seroma in the literature, it can be described as a painful condition that causes fluctuation and tension after mastectomy and eventually requires needle aspiration [5]. As seroma generally regresses within a few weeks after aspiration, most surgeons consider it more tolerable than other serious complications [6]. However, seroma can lead to more serious complications such as wound infection, lymphedema, flap necrosis, prolonged hospital length of stay, sepsis, and delay in the initiation of adjuvant treatment [7, 8]. Various methods have been used to prevent seroma formation, including flap fixation with sutures, application of bovine thrombin, fibrin glue, talc, tranexamic acid, tetracycline, or other various antineoplastic agents, to enhance local fibrosis.

The objective of the research was to evaluate the effects of local fibrin glue, tetracycline, and talc applications, flap fixation technique and alcoholic iodine on reducing seroma formation after mastectomy and axillary dissection. In addition, we aimed to determine the level of efficacy for these applications, as well as to identify the most appropriate method to be used in operations with high risk of seroma formation.

\section{Materials and Methods}

\section{Experimental Animals and Groups}

This experimental study was conducted on 60 female Wistar albino rats weighing 200-250 grams at the age of 12-16 weeks. All the rats received a standard chow and water and were maintained in a 12-hour light/dark cycle at a constant temperature $\left(22 \pm 2^{\circ} \mathrm{C}\right)$.

The rats were divided into six groups: Group 1 (the control group) ( $\mathrm{n}=10)$; Group 2 (the flap fixation group) $(\mathrm{n}=10)$; Group 3 (the fibrin glue group) ( $\mathrm{n}=10)$; Group 4 (the tetracycline group) ( $\mathrm{n}=10)$; Group 5 (the alcoholic iodine group) $(\mathrm{n}=10)$; Group 6 (the talc group) $(\mathrm{n}=10)$.

\section{Operation Technique}

Following anesthesia with intraperitoneal ketamine (Ketalar ${ }^{\circledR}$, Parke-Davis \& Co. Inc., $90 \mathrm{mg} / \mathrm{kg}$ ) and xylazine (Rompun ${ }^{\circledR}$, Bayer $10 \mathrm{mg} / \mathrm{kg}$ ), unilateral mastectomy and axillary dissection were performed on all the rats using the method described by Harada [9]. After providing hemostasis in the control group, no additional intervention was applied. In the flap fixation group, the skin flap was fixated to the underlying muscle tissue with 4/0 Vicryl sutures. In the fibrin glue group, fibrin glue was applied locally to cover the whole surgical area. In the tetracycline group, the surgical site was rinsed with $3 \mathrm{cc}$ of the solution that was prepared by dissolving $2 \mathrm{~g}$ of tetracycline in $150 \mathrm{cc}$ of saline. In the talc group, the surgical site was rinsed with $3 \mathrm{cc}$ of a homogenous solution prepared by mixing $10 \mathrm{~g}$ of talc in $100 \mathrm{cc}$ of saline. In the alcoholic iodine group, the surgical site was washed with $3 \mathrm{cc}$ of solution containing $10 \%$ povidone-iodine and $30 \%$ ethyl alcohol. The skin was closed with 3/0 sharp silk or Prolene suture.

After the operation, the rats were monitored for 10 days. During this time, the viability of rats, arm movements, wound healing conditions, wound infection, flap necrosis, and seroma formation were recorded. On the $10^{\text {th }}$ postoperative day, the surgical area was reopened under ketamine-xylazine anesthesia. Seroma fluids were aspirated with sterile injectors and the amount of the aspirated fluid was recorded. Seroma fluid samples were analyzed for interleukin (IL) $1 \beta$, vascular endothelial growth factor (VEGF), and C-reactive protein (CRP) levels. Tissue samples were obtained from the skin overlaying the dissection area, the axilla, and the thoracic wall for histopathological examination. After all these procedures, the rats were sacrificed via exsanguination.

\section{Histopathological Examination}

The segment fixated in a 10\% formaldehyde solution was embedded in paraffin, and serial sections with a 5-micrometer thickness were obtained. The sections were either stained with hematoxylin and eosin (H\&E) or Masson's trichrome dye to detect early collagen content. The wound healing score was assessed as described by Greenhalg et al. [10] (Table 1). The absence of inflammatory cells, profound fibroblastic activity, new collagen formation, and neovascularization were accepted as excellent wound healing, whereas the opposite condition was accepted as poor healing.

\section{Biochemical Analysis Methods}

For biochemical analysis, the aspirated seroma fluids were centrifuged at 4,000 rpm. As acute phase reactants, IL-1 $\beta$, $\mathrm{CRP}$, and VEGF (which indicate the presence of inflammation) were measured in seroma fluid using rat-specific ELISA kits.

\section{Statistical Methods}

IBM SPSS Statistics version 21 (IBM Corp., Armonk, NY) software package was used for data analysis. The distribution characteristics of the measured amounts of seroma fluid, and seroma fluid IL-1 $\beta$, CRP and VEGF levels were assessed with the Kolmogorov Smirnov and Shapiro-Wilk tests. Since all the data showed normal distribution, analysis of variance with the Tukey HSD post-hoc test was used for comparisons between the groups. As wound healing scores were categorical data, they were evaluated using the Kruskal-Wallis test. Data were expressed as mean \pm SD (standard deviation) for 
Table 1. Scoring of wound healing.

\begin{tabular}{cccccc}
\hline \multirow{2}{*}{ Score } & $\begin{array}{c}\text { Inflammatory } \\
\text { cells }\end{array}$ & Neutrophil & $\begin{array}{c}\text { Fibroblastic } \\
\text { activity }\end{array}$ & $\begin{array}{c}\text { Neo- } \\
\text { vascularization }\end{array}$ & $\begin{array}{c}\text { Collagen } \\
\text { bands }\end{array}$ \\
\hline 1 & +++ & +++ & - & $-/+$ & - \\
2 & +++ & +++ & $+/++$ & $+/++$ & - \\
3 & ++ & $+/++$ & +++ & +++ & + \\
4 & $+/++$ & $-/+$ & $++/+++$ & $+/++$ & ++ \\
5 & $-/+$ & $-/+$ & $+/++$ & + & +++ \\
\hline
\end{tabular}

continuous variables, or as median (minimum-maximum) for categorical variables. A $p$-value of less than 0.05 was accepted as statistically significant.

\section{Results}

\section{Macroscopic Findings}

Among all the rats included in the study, two rats in the alcoholic iodine group died within the first two hours after the surgical procedure. In addition, two rats each from the alcoholic iodine group and the talc group developed wound dehiscence.

Table 2 presents the amounts of seroma fluid, and seroma fluid VEGF, CRP, and IL- $1 \beta$ levels (mean \pm SD) across the study groups, whereas Table 3 shows $p$-values obtained from the comparisons of the studied parameters.

In comparison to the control group, the amount of seroma fluid was significantly higher in the flap fixation group and the tetracycline group, whereas it was significantly lower in the alcoholic iodine group and the talc group $(\mathrm{p}<0.05)$. There was no statistically significant difference between the fibrin glue group and the control group. When comparing the groups in relation to each other, there was no difference between the flap fixation and the tetracycline group $(\mathrm{p}=0.96)$, while the amount of seroma fluid was significantly lower in these two groups as compared to the rest of the groups.

\section{Biochemical Findings}

The control group had the lowest mean VEGF levels. All the groups with local substance application had significantly higher mean VEGF levels as compared to the control group $(\mathrm{p}<0.05)$. There was no statistically significant difference between the flap fixation group and the control group ( $\mathrm{p}=0.45$ ). VEGF levels were significantly lower in the flap fixation group as compared to the other groups (the talc group was an exception).

The CRP levels were not statistically different between the groups.

The tetracycline group had the lowest mean seroma fluid IL-1 $\beta$ level, which was significantly lower as compared to the fibrin glue group, the alcoholic iodine group, and the talc group $(\mathrm{p}<0.05)$. However, there was no significant difference in comparison to the flap fixation group $(\mathrm{p}=0.44)$.

\section{Histopathological Findings}

Histopathological examination of the groups revealed the presence of foreign body reaction and a failure of wound healing in the talc group. Therefore, the healing score assessment was not applied to this group.

The best wound healing scores were observed in the tetracycline group and the flap fixation group (Figures 1-3).

Figure 1. Infected seroma.

A: $H \& E \times 100$; B: Masson's trichrome $\times 100$; Arrow shows unhealed (Score 2) wound.

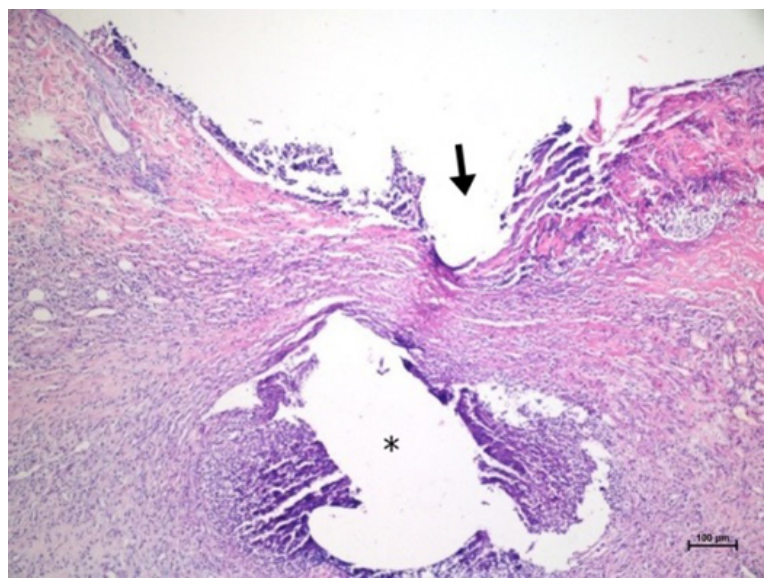

(A)

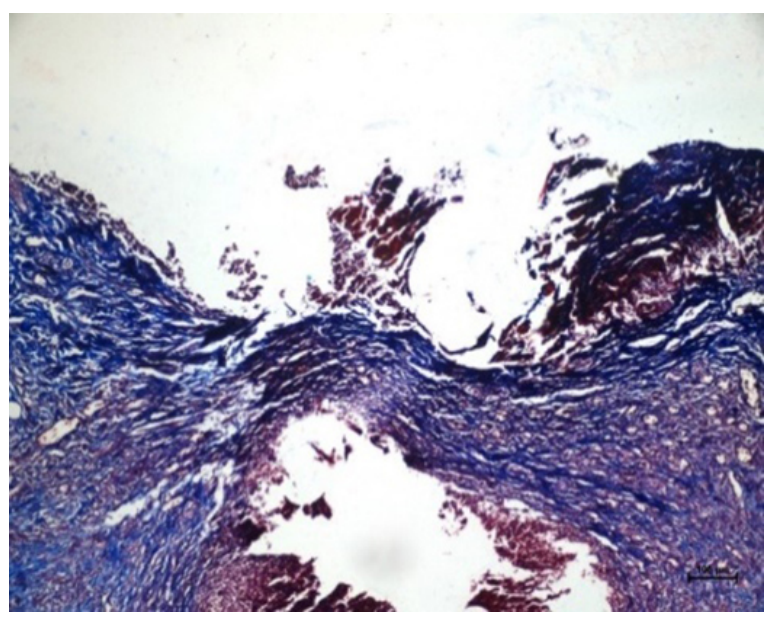

(B) 
Figure 2. Wound healing in the flap fixation group. A: $\mathrm{H} \& \mathrm{E} \times 100$; B: Masson's trichrome $\times 100$; Arrows display profound collagen deposition (Score 5).

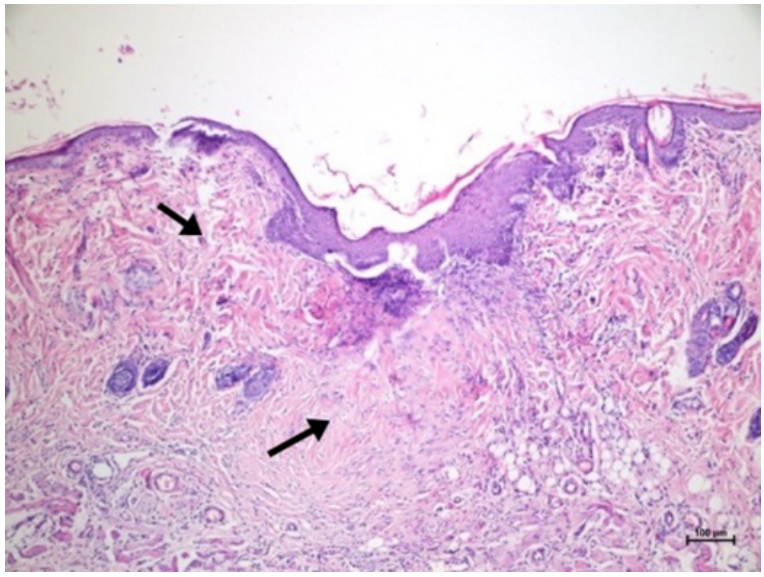

(A)

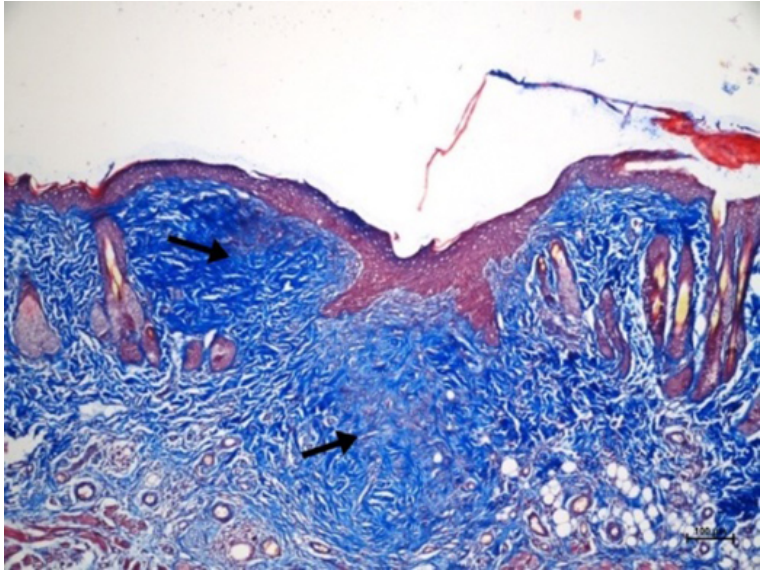

(B)

There was no statistically significant difference between these two groups $(\mathrm{p}=0.20)$. They showed a significantly better wound healing score as compared to the other groups $(\mathrm{p}<0.05)$.

\section{Discussion}

Seroma is an abnormal accumulation of serous fluid within the dead space that is formed under the skin flap, in the axilla after mastectomy, or within the breast tissue after conservative surgery. It is one of the most common wound site complications observed in the early postoperative period. This complication is a reason for the prolonged healing process and length of hospital stay [7]. Although the pathogenesis of seroma formation is not clearly known, injury to the axillary lymphatic channels seems to be the most important cause [9]. Another cause is the inflammatory process, which causes increased vascular permeability due to increased blood and tissue concentrations of mediators such as histamine, prostaglandin, and
Figure 3. Wound healing in the tetracycline group. A: $\mathrm{H} \& \mathrm{E} \times 100$; B: Masson's trichrome $\times 100$; Arrows display moderate collagen deposition (Score 4 ).

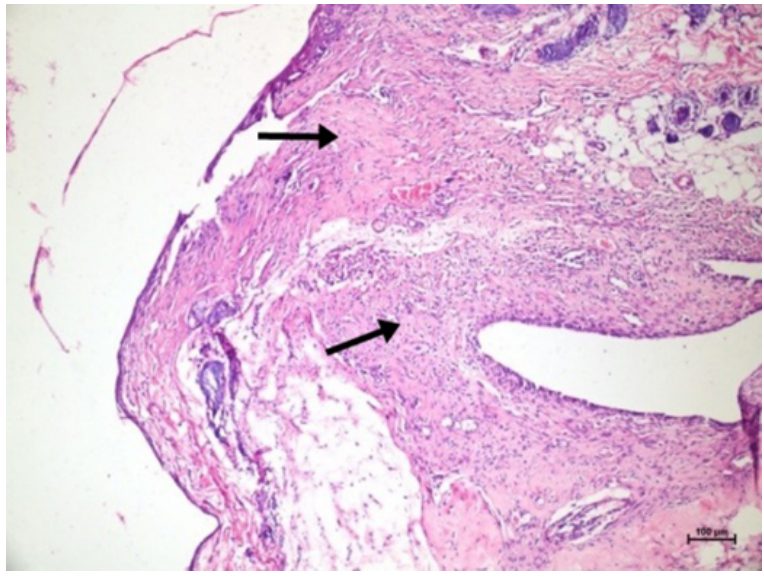

(A)

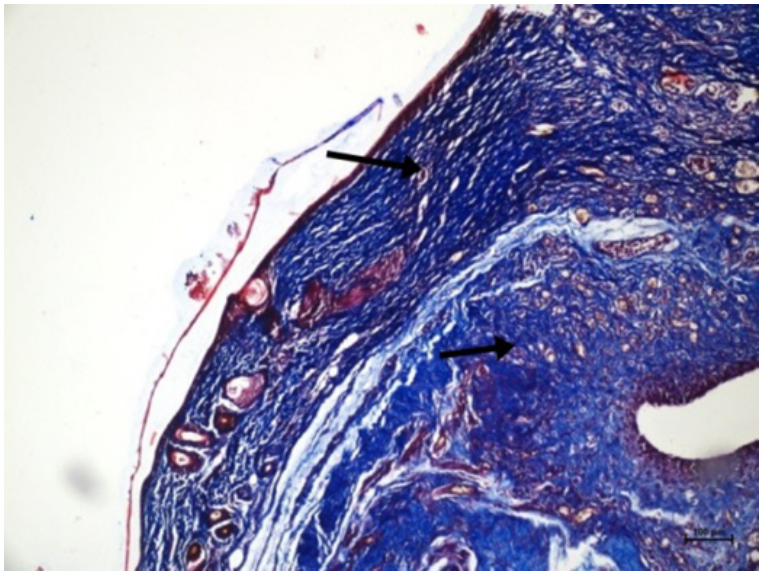

(B)

adenosine. Inflammation alters local ionic concentrations and creates a gradient in the potential space that draws more fluid out of the cells. There are 3 main predisposing factors for the formation of high amounts of seroma in the surgical site after mastectomy and axillary dissection. These are: (I) the interruption of lymphatic and vascular channels as a primary source of fluid leakage into the surgery site; (II) the formation of a potential dead space with dissection of the tissues, which creates a reservoir for accumulation of the interstitial fluid; and (III) the acceleration of seroma accumulation by elevation and enlargement of the skin flap. After elevation of the skin flap, local inflammation causes increased release of chemoattractant agents, and a series of inflammatory events increase serous drainage into the surgical site [11, 12]. Elimination of the potential space, effective hemostasis, and ligation of the damaged lymphatic channels during dissection are important in preventing seroma formation.

Many experimental and clinical studies have examined various surgical techniques and agents for their efficacy in pre- 
Table 2. Amount of seroma and seroma fluid VEGF, CRP and IL- $1 \beta$ concentrations across the groups.

\begin{tabular}{lcccc}
\hline Group & $\begin{array}{c}\text { Amount of seroma } \\
(\mathrm{cc})\end{array}$ & VEGF level & CRP level & IL-1 $\beta$ level \\
\hline $\begin{array}{l}\text { Group 1 (Control) } \\
\mathrm{n}=10\end{array}$ & $1.39 \pm 0.19$ & $232.49 \pm 47.11$ & $120.68 \pm 20.11$ & $1019.97 \pm 129.28$ \\
\hline $\begin{array}{l}\text { Group 2 (Flap fixation) } \\
\mathrm{n}=10\end{array}$ & $0.67 \pm 0.17$ & $277.79 \pm 29.32$ & $147.07 \pm 46.92$ & $1013.71 \pm 96.67$ \\
\hline $\begin{array}{l}\text { Group 3 (Fibrin glue) } \\
\mathrm{n}=10\end{array}$ & $1.66 \pm 0.39$ & $358.29 \pm 59.67$ & $131.34 \pm 26.16$ & $1179.26 \pm 162.88$ \\
\hline $\begin{array}{l}\text { Group 4 (Tetracycline) } \\
\mathrm{n}=10\end{array}$ & $0.58 \pm 0.18$ & $354.14 \pm 55.74$ & $128.43 \pm 19.76$ & $913.36 \pm 117.62$ \\
\hline $\begin{array}{l}\text { Group 5 (Alcoholic iodine) } \\
\mathrm{n}=8\end{array}$ & $2.11 \pm 0.18$ & $373.60 \pm 35.34$ & $127.23 \pm 20.97$ & $1183.67 \pm 105.54$ \\
\hline $\begin{array}{l}\text { Group 6 (Talc) } \\
\mathrm{n}=10\end{array}$ & $2.15 \pm 0.18$ & $333.61 \pm 83.83$ & $145.57 \pm 25.09$ & $1203.95 \pm 101.76$ \\
\hline
\end{tabular}

Table 3. P-values in comparisons of the groups.

\begin{tabular}{ccccccc}
\hline Compared Groups* & $\begin{array}{c}\text { Amount of } \\
\text { seroma }\end{array}$ & VEGF & CRP & IL-1 $\beta$ & $\begin{array}{c}\text { Histopathological } \\
\text { score }\end{array}$ \\
\hline 1 & 2 & $<0.05$ & 0.45 & 0.31 & 1 & 0.77 \\
1 & 3 & 0.14 & $<0.05$ & 0.95 & 0.05 & 0.44 \\
1 & 4 & $<0.05$ & $<0.05$ & 0.99 & 0.37 & $<0.05$ \\
1 & 5 & $<0.05$ & $<0.05$ & 0.99 & 0.06 & $<0.05$ \\
1 & 6 & $<0.05$ & $<0.05$ & 0.37 & $<0.05$ & - \\
2 & 3 & $<0.05$ & $<0.05$ & 0.81 & $<0.05$ & $<0.05$ \\
2 & 4 & 0.96 & $<0.05$ & 0.68 & 0.44 & 0.2 \\
2 & 5 & $<0.05$ & $<0.05$ & 0.68 & 0.05 & - \\
2 & 6 & $<0.05$ & 0.23 & 1 & $<0.05$ & $<0.05$ \\
3 & 4 & $<0.05$ & 1 & 1 & $<0.05$ & - \\
3 & 5 & $<0.05$ & 0.99 & 1 & 1 & $<0.05$ \\
3 & 6 & $<0.05$ & 0.91 & 0.87 & 0.99 & - \\
4 & 5 & $<0.05$ & 0.97 & 1 & $<0.05$ & - \\
4 & 6 & $<0.05$ & 0.96 & 0.75 & $<0.05$ & 0.99 \\
5 & 6 & 0.99 & 0.65 & 0.74 & 0.99 & - \\
\hline
\end{tabular}

Notes: $* 1$ : the control group; 2: the flap fixation group; 3: the fibrin glue group; 4: the tetracycline group; 5: the alcoholic iodine group; 6: the talc group.

vention of seroma formation after mastectomy. Flap fixation technique involves fixation of the flaps to the chest wall with subcutaneous sutures or tissue glue for the purpose of closing the dead space and reducing seroma formation. Although the scientific body of evidence favoring flap fixation after mastectomy is convincing, a systematic review of flap fixation technique [13] suggests that mechanical flap fixation seems to reduce seroma formation and seroma aspiration after mastectomy. In addition, randomized studies [14-16] reported that mastectomy followed by flap fixation with either sutures or adhesive tissue glue reduces the number of seromas requiring needle aspirations as compared to cases of simple wound closure. The use of adhesive tissue glue and sutures seems to be equally effective [14].

As sclerosant agents, tetracycline, talc, iodopovidone are used to achieve chemical pleurodesis by triggering an inflammatory response $[17,18]$. According to Rice et al. and McCarthy et al., local tetracycline application had no effect on seroma formation after mastectomy and was associated with severe pain $[19,20]$. A study with erythromycin showed that seroma formation was reduced with erythromycin application [21]. Corynebactcrium parvum (CP) has non-specific immunostimulant and anti-tumoral activities and has been documented for its potent sclerosing agent as well. Tekin et al. [22] showed reduced seroma formation with $\mathrm{CP}$ in a rat mastectomy model. Although a case report [23] suggested, talc might be a safe, cost-effective, and minimally invasive solution, a randomized phase II study [24] reported there was not sufficient evidence to support its use for seroma prevention following modified radical mastectomy in patients with breast 
cancer.

Seroma occurs during acute phase of inflammation. Accumulation of inflammatory mediators within the potential space following surgery results in increased permeability and leads to serous fluid collection. Steroids and non-steroid antiinflammatory drugs have been used in several studies to prevent seroma formation since they inhibit inflammation [25].

In the present study, we evaluated the effects of fibrin glue, tetracycline, and talc substance application and flap fixation technique on postoperative seroma formation. The previous methods have been found to be beneficial in reducing seroma in rats after radical mastectomy and axillary node dissection. Additionally, we evaluated alcoholic iodine and, although its effect on seroma has not been examined before, we thought it could benefit due to its cicatrizing property.

When evaluating the amount of seroma in different groups of our study, we observed that tetracycline application and flap fixation technique reduced the amount of seroma. By contrast, fibrin glue, talc, and alcoholic iodine applications increased postoperative seroma. There was no statistically significant difference between the tetracycline group and the flap fixation group regarding the reduction in seroma. Both groups were found to be statistically better than the rest of the groups including the control group.

The lowest concentrations of VEGF in the seroma fluid were observed in the control group and the flap fixation group. There was no statistically significant difference between these two groups. As compared to these two groups, significantly higher values were observed in the local application groups. However, this difference did not correlate with the results for seroma amount and wound healing scores.

Seroma fluid IL-1 $\beta$ values were significantly lower in the flap fixation group and the tetracycline group as compared to the other groups. These values were associated with the results regarding seroma amount and wound healing scores. Higher IL- $1 \beta$ values were measured in groups that had more seroma due to prolonged inflammation. The flap fixation group and the tetracycline group had significantly lower values as compared to the alcoholic iodine group, the talc group, and the fibrin glue group.

There was no statistically significant difference in seroma fluid CRP values between the groups. They were not found to be useful for assessment of wound healing.

The evaluation of histopathological scores of the groups revealed that optimal wound healing occurred in the flap fixation group and the tetracycline group. Median scores in the fibrin glue group and the alcoholic iodine group were lower than those in the control group. The examination in the talc group revealed the foreign body reaction and delayed wound healing in this group. Therefore, this group was excluded from scoring for wound healing. The flap fixation group and the tetracycline group showed significantly superior wound healing as compared to the other groups.

\section{Conclusions}

We observed that local application of alcoholic iodine and talc substances caused increased wound site problems and postoperative seroma in the mastectomy model. Although fibrin glue did not cause wound site problems, it increased seroma formation. These three substances were concluded to have no benefit on postoperative seroma formation. Local tetracycline application and flap fixation technique were found to reduce postoperative seroma and contribute to wound healing. We concluded that flap fixation technique and/or local tetracycline application may be a viable option to reduce postoperative seroma formation.

\section{Ethical Statement}

The study was approved by the Süleyman Demirel University Animal Experiments Local Ethics Committee (Issue date: 05.06.2014, No. 21438139-149).

\section{Conflict of Interest}

The authors declare that no conflicts exist.

\section{Financial Disclosure}

The authors declared no financial support.

\section{References}

[1] Nevola Teixeira LF, Sandrin F. The role of the physiotherapy in the plastic surgery patients after oncological breast surgery. Gland Surg 2014;3:43-47. Available from: https://doi.org/10.3978/j.issn.2227-684X.2014.02.12

[2] Tukenmez M, Agcaoglu O, Aksakal N, Destek S, Cabioglu N, Barbaros U, et al. The use of Ligasure vessel sealing system in axillary dissection; effect on seroma formation. Chirurgia (Bucur). 2014;109(5):620-625.

[3] Van Bemmel AJM, van de Velde CJH, Schmitz RF, Liefers GJ. Prevention of seroma formation after axillary dissection in breast cancer: A systematic review. European Journal of Surgical Oncology (EJSO) [Internet]. 2011 Oct;37(10):829-835. Available from: https://doi.org/10.1016/j.ejso.2011.04.012

[4] Gardner A, Pass HA, Prance S. Techniques in the prevention and management of breast seroma: An evaluation of current practice. The Women's Oncology Review [Internet]. $2005 \mathrm{Jan} ; 5(3): 135-143$. Available from: https://doi.org/10.1080/14733400500216814

[5] Kuroi K, Shimozuma K, Taguchi T, Imai H, Yamashiro H, Ohsumi S, et al. Pathophysiology of seroma in breast cancer. Breast Cancer [Internet]. 2005 Oct;12(4):288-293. Available from: https://doi.org/10.2325/jbcs.12.288 
[6] Kuroi K, Shimozuma K, Taguchi T, Imai H, Yamashiro H, Ohsumi S, et al. Evidence-Based Risk Factors for Seroma Formation in Breast Surgery. Japanese Journal of Clinical Oncology [Internet]. 2006 Apr 1;36(4):197-206. Available from: https://doi.org/10.1093/jjco/hyl019

[7] Anjani J, Amit O, Kuber S, Achal G. Factors affecting seroma formation after modified radical mastectomy in patients of carcinoma breast: A prospective study. IJSS Journal of Surgery. 2016;2(1):1-5. Available from: http://surgeryijss.com/index.php/IJSS/article/view/110

[8] Van Bastelaar J, Beckers A, Snoeijs M, Beets G, Vissers Y. Flap fixation reduces seroma in patients undergoing mastectomy: a significant implication for clinical practice. World Journal of Surgical Oncology [Internet]. $2016 \mathrm{Mar}$ 8;14(1). Available from: https://doi.org/10.1186/s12957016-0830-8

[9] Harada RN, Pressler VM, McNamara JJ. Fibrin glue reduces seroma formation in the rat after mastectomy. Surg Gynecol Obstet. 1992;175(5):450-454.

[10] Greenhalgh DG, Sprugel KH, Murray MJ et al. PDGF and FGF stimulate wound healing in the genetically diabetic mouse. Am J Pathol. 1990;136(6):1235-1246.

[11] Gonzalez EA, Saltzstein EC, Riedner CS, Nelson BK. Seroma Formation Following Breast Cancer Surgery. The Breast Journal [Internet]. 2003 Sep;9(5):385-388. Available from: https://doi.org/10.1046/j.15244741.2003.09504.x

[12] Eroğlu E, Oral S, Ünal E, Kalayci M, Öksüz O, Tilmaz M. Reducing seroma formation with fibrin glue in an animal mastectomy model. European Journal of Surgical Oncology (EJSO) [Internet]. 1996 Apr;22(2):137-139. Available from: https://doi.org/10.1016/S07487983(96)90567-3

[13] Van Bastelaar J, Theunissen LLB, Snoeijs MGJ, Beets GL, Vissers YLJ. Flap Fixation Using Tissue Glue or Sutures Appears to Reduce Seroma Aspiration After Mastectomy for Breast Cancer. Clinical Breast Cancer [Internet]. 2017 Jul;17(4):316-321. Available from: https://doi.org/10.1016/j.clbc.2017.01.005

[14] Granzier RWY, van Bastelaar J, van Kuijk SMJ, Hintzen KFH, Heymans C, Theunissen LLB, et al. Reducing seroma formation and its sequelae after mastectomy by closure of the dead space: The interim analysis of a multi-center, doubleblind randomized controlled trial (SAM trial). The Breast [Internet]. 2019 Aug;46:81-86. Available from: https://doi.org/10.1016/j.breast.2019.05.002

[15] Mustonen PK, Härmä MA, Eskelinen MJ. The Effect of Fibrin Sealant Combined with Fibrinolysis Inhibitor on Reducing the Amount of Lymphatic Leakage after Axillary Evacuation in Breast Cancer. Scandinavian Journal of Surgery [Internet]. 2004 Sep;93(3):209-212. Available from: https://doi.org/10.1177/145749690409300307

[16] Segura-Castillo JL, Estrada-Rivera O, CastroCervantes JM, Cortés-Flores AO, Velázquez-Ramírez GA, González-Ojeda A. Reduction of lymphatic drainage posterior to modified radical mastectomy with the application of fibrin glue. Cir Cir. 2005;73(5):345-350. Available from: https://pubmed.ncbi.nlm.nih.gov/16336797/

[17] Lamb C, Li A, Thakkar D, Lee P. Pleurodesis. Seminars in Respiratory and Critical Care Medicine [Internet]. 2019 Jun;40(03):375-385. Available from: https://doi.org/10.1055/s-0039-1693997

[18] Mierzejewski M, Korczynski P, Krenke R, Janssen JP. Chemical pleurodesis - a review of mechanisms involved in pleural space obliteration. Respiratory Research [Internet]. 2019 Nov 7;20(1). Available from: https://doi.org/10.1186/s12931-019-1204-x

[19] Rice DC, Morris SM, Sarr MG, Farnell MB, van Heerden JA, Grant CS, et al. Intraoperative topical tetracycline sclerotherapy following mastectomy: A prospective, randomized trial. Journal of Surgical Oncology [Internet]. 2000 Apr;73(4):224-227. Available from: https://doi.org/10.1002/(SICI)10969098(200004)73:4;224::AID-JSO7;3.0.CO;2-0

[20] McCarthy PM, Martin JK Jr, Wells DC, et al. An aborted, prospective, randomized trial of sclerotherapy for prolonged drainage after mastectomy. Surg Gynecol Obstet. 1986;162(5):418-420.

[21] Ali-Khan AS, Orlando A, Kenealy J. Erythromycin sclerotherapy in the management of seroma. Journal of Plastic, Reconstructive \& Aesthetic Surgery [Internet]. 2009 Mar;62(3):e55-e58. Available from: https://doi.org/10.1016/j.bjps.2008.08.016

[22] Tekin E, Kocdor MA, Saydam S, Bora S, Harmancioglu O. Seroma Prevention by Using Corynebacterium parvum in a Rat Mastectomy Model. European Surgical Research [Internet]. 2001;33(3):245-248. Available from: https://doi.org/10.1159/000049713

[23] Catsman CJLM, Beek MA, Rijken AM. Talc seromadesis in patients with chronic seroma formation after breast surgery. SpringerPlus [Internet]. 2016 Jan 4;5(1). Available from: https://doi.org/10.1186/s40064-015-1648-5

[24] Garza-Gangemi AM, Barquet-Muñoz SA, VillarrealColín SP, Medina-Franco H, Cortés-González R, VilarCompte D, Cantú-de-León D. Randomized Phase II Study of Talc Versus Iodopovidone for the Prevention of Seroma Formation Following Modified Radical Mastectomy. Rev Invest Clin. 2015;67(6):357-365. Available from: https://clinicalandtranslationalinvestigation.com/ 
[25] Hidar S, Soussi K, Bidi M. Ketoprofen'in radikal meme cerrahisi sonrasında drenaj hacmine etkisi. Journal of the Turkish German Gynecological Association. 2007;8:7175.
Received: $2020-10-26$

Revised: $2020-11-23$

Accepted: 2021-01-12 